\title{
South Africa and Rwanda: Truth and Reconciliation Commissions, Peacebuilding, Religious and Local African Authorities in conflict situations
}

\author{
Emmanuel Lohkoko AWOH \\ Walter Gam NKWI
}

\begin{abstract}
This paper explores the character of Truth and Reconciliation Commissions (TRC) in South Africa and the gacaca courts in Rwanda in a bid to understand how indigenous values emphasised within some of the different indigenous African cultures like Ubuntu (a quality that includes the essential human virtues - compassion and humanity) in South Africa accounted for the success of these institutions in these countries. What seems to be invariably missing in the other experiments of TRC across the continent is the lack of cultural considerations in their construct which this article argues that it accounted for their failure. While post conflict reconciliation remains relevant, as communities move from war to peace and from repression to democracy and vice versa by healing relationships and social structures, many of the experiences with TRC, especially in non-Western contexts have ended up not being able to promote peace through genuine social repairs. In cases like Liberia and Ivory Coast, among many others, these institutions have been criticised as sidelining indigenous cultural values to yield the desired transformative effect. While much has been documented about the relative strengths of tribunals and TRCs, one area that has received little attention is the religious and cultural relevance of these institutions. There seems to be inadequate space created for cultural and religious traditions within these liberal mechanisms of peace building. While relying solely on secondary data in the conduct of this research, we argue that the present peace approaches in Africa have not adequately considered the cultural factors of the continent in their formation. Even within the advent of mo-

Emmanuel Lohkoko AWOH

PhD Candidate

School of Social and Political Sciences

University of Melbourne

Email: eawoh@student.unimelb.edu.au

Walter Gam NKWI

Department of History

University of Buea, Cameroon

Email: nkwiwally@yahoo.com,

nkwi.walters@ubuea.cm

Conflict Studies Quarterly

Issue 20 , July 2017 , pp. 20-33

DOI:10.24193/csq.20.2

Published First Online: 2017/07/3
\end{abstract}


dernity and globalisation, traditional systems and their values could still be negotiated within the new status quo ante without losing its value. Their strength resides in the fact that they are not created solely by laws, but are generated by the respective communities.

Keywords: Truth and Reconciliation Commission (TRC), Conflict, Peace Building, African Authorities.

\section{Introduction}

Conflicts have been a daily occurrence in Africa since most countries gained their political independence. For instance, during the four decades between the 1960s and the 1990s, there have been about 80 violent changes of government in the 48 Sub-Saharan African countries (Adedeji, 1999). During the same period, many of these countries also experienced different types of civil strife, conflicts and wars. Causal statistics suggest that, at the beginning of the new millennium, there were 18 countries facing armed rebellion while 11 were facing severe political crises and 19 enjoying more or less various states of stable political conditions (Adedeji, 1999). Some of the countries in the last two categories have only recently moved from the first category. Zartman (2000) drawing from a United Nations Development report (UNDP) paints the picture in following words:

A snapshot of explosive conflicts in today's Africa present a worrying picture of Eritrea and Ethiopia of the DRC, Rwanda, Uganda, Namibia, Zimbabwe, Sudan, the last with the longest running civil war on the continent; of Sierra Leone with gruesome atrocities against civilians; of Somalia, Burundi, Guinea Bissau and Lesotho, the latter reeling from South Africa's recent intervention (p. 2).

As much as the conflicts have appeared, they have not been going on ad infinitum. There have always been attempts to resolve them and most of the time, when the scars left because the conflicts are so deep, truth and reconciliation commissions are set up for people implicated in conflict to confess and then reconcile. Amongst the conflicts, the ones that bedevilled the Republics of South Africa and Rwanda were too protracted and complex and, therefore, necessitate academic attention.

This paper begins with an analytical framework in understanding the meaning of Reconciliation and the concepts of individualism, universalism and retributive justice that overlaps between liberal and neo-liberal philosophies as the main foundation of this work. We also highlight on the gacaca traditional courts in Rwanda which drew inspirations from the local cultures in the trials of those who were implicated in the1994 genocide that consumed millions of people. This is followed by an analysis of the TRC in South Africa and the concept of Ubuntu. We argue that the success of the TRC was largely due to the use of the concept of Ubuntu. We also look at the religious element in the TRC in South Africa and how it impacted the outcome.

In this article, we further argue that though these new structures were built on the liberal and neo-liberal ideas, they have not really yielded the intended goal of peace 
building. We cannot apportion all the blames to these liberal and neo-liberal ideas of individualism, universalism and the retributive justice approach to account for the failure of peace building in some of these African states, like Chad, Liberia and Ivory Coast, where the experiments have been unsuccessful.

Some custodians of African traditions have sacrificed their cultural heritages in exchange for political power. Most chiefs have lost their control over their subjects, since most chiefs are now often divided along party lines. Their inability to maintain political neutrality and to provide political tolerance for all political views has cost them the respect, dignity of the institution and the individual office holders. Chiefs have also undermined in this regard their strategic position as representatives of all people within their Chiefdoms.

For the past few decades, scholars have highlighted the relative importance of international tribunals and TRC in post-conflict societies. While both are focused on resolving crime and conflict, they differ in the character and formation, as transitional justice mechanisms. TRC views crime essentially as a violation of people and relationships between people. Its primary objective is to correct such violations and to restore relationships. As such, it necessarily involves victims and survivors, perpetrators and the community in the quest for a level of justice that promotes repair, trust-building and reconciliation. International tribunals, on the other hand, seek to apply the established law as a basis for reaffirming the legal basis for human decency. It is concerned with punishment for an infraction or abuse of law and largely focuses upon the treatment that should be given to the offender or perpetrator. It is a retroactive approach in which legal proceedings play a central role and is based upon the contention that mechanisms such as courts, national criminal laws and international criminal laws are essential for dismantling impunity and for putting in place measures for the non-repetition of rights abuses in the future.

However, very little attention has been paid to the cultural relevance of these institutions to the people they are out to serve, especially in post-conflict transitional peace building (Hancock \& Zeren, 2010). The degree to which cultural and religious norms are considered in the role of these institutions in dispensing post-conflict transitional justice has come under severe criticism. The attention to cultural values within the framework of these institutions has remained elusive. The character of these institutions in promoting peace through retributive justice ${ }^{1}$ is much more embedded in liberal and neo-liberal ideas of individualism and universalism (rooted in the Western cultures) and is perceived in that context as the appropriate road map to rebuilding peace in post-conflict zones. The post-World War II Nuremberg trials, for example, which

1 Retributive justice refers mostly to systems that rely solely on punishment as the best way of responding to crimes 
were established to handle Nazi war crimes and criminals as well as the international criminal tribunals for former Yugoslavia, were in this liberal philosophy (Hancock \& Zeren, 2010). While this is true in Western cultures, its applicability as a "one size fit all" universally acclaimed procedure in dispensing justice in post-conflict Africa becomes problematic and ineffective and grossly out of context. Consequently, it cannot yield any meaningful results.

The reasons for this ineffectiveness are that universalism, as a character of these institutions, become culturally alienating because it does not take into considerations other cultural specificities. Secondly, the individualist character in some of these institutions, like the TRCs, undermines the emphasis of communal wellbeing across African societies which concepts like Ubuntu in South Africa and gacaca in Rwanda incarnate. Lastly, in most of the experiments of TRCs in Africa, retributive justice approach has often been used as a means to foster peace, which does not resonate with the reparative or restorative justice systems ${ }^{2}$ that is emphasised within some of the different indigenous African cultures, like Ubuntu in South Africa. These institutions, therefore, assume the ethical primacy of human beings against the pressure of communal harmony, grounded within different African cultures like the gacaca in Rwanda and Ubuntu in South Africa (Kyed, 2006).

This paper argues that the present peace approaches in Africa have not adequately considered the cultural factors of the continent in their formation. Even within the advent of modernity and globalisation, traditional systems and their values could still be negotiated within the new status quo ante without losing its value, in a bid to mitigate the spiral effects of conflicts in Africa (Humphrey, 2003). Their strength resides in the fact that they are not created solely bylaws, but are generated by the respective communities.

\section{Analytical framework}

Over the years, scholars have been trying to understand the concept of Truth and Reconciliation and how it functions within different cultures. It is the belief of some Africans scholars, like Boaduo (2010), that these new peacebuilding structures are grounded on liberal and neo-liberal concepts that originated outside the African context. This section looks at the meaning of reconciliation, the overlap in some liberal and neo-liberal ideas and how they are related with the former. In understanding reconciliation, we drew inspiration from the works of Kirmayer (2004), Staub, Pearlman and Miller (2003), Philpott (2006), Murphy (2010), Hayner (1999) and Hamber (2007).

2 Carver (2008) asserts that reparative justice focuses more on striking a balance between the offenders and victims. The goal is often to satisfy the needs of the conflicting parties to avoid future conflicts that could potentially destabilise the community 
These authors collectively and individually examine the characteristics and features of reconciliation and what could be necessary in ensuring sincere and lasting reconciliation in post-conflict zones.

Enduring reconciliation is a negotiated process through many complex systems that require a plethora of approaches constructed through underlying cultural beliefs (Kirmayer, 2004; Juma, 2002). Realistic healing methods are grounded in a broader cultural system that specifically identify the ills and prescribes appropriate interventions. Staub et al. (2003) argue that sincere reconciliation from trauma of victimisation has the potential of averting retaliation, especially if perpetrators continue to cohabit with survivors within the same geographical space.

For reconciliation to be effective, all parties must be committed in building already damaged relationships in a bid to re-establish societal cohesion. Murphy (2010) considers political reconciliation as forgiveness and the overcoming of a wide spread negative emotions in order to rekindle destroyed political relationships. He also echoes the necessity to establish normalised relationships and legal trust within political communities and to put in place democratic political values on the plat form of free and equal citizenship. Hayner $(1999,2002)$ mirrors reconciliation as an evaluation of how the past is handled within a public sphere, in order to evaluate the influence of the past on political and other relationships.

Perpetrators must move from the blame politics and exclusion of victims as 'others' or enemies, to assume responsibilities and empathise with their victims to bring about true reconciliation (Kyed, 2006). Philpot (2006) sees reconciliation as comprising varying political processes, such as restorative and retributive justice systems of restoring right relationships within the society, which often must not go through very official procedures. It is in this light that Kriesberg (2007) argues that reconciliation as a process must develop mutual conciliatory accommodation between formerly disputing parties. He sustains that reconciliation should move towards a relatively cooperative relationship, established after a rupture in cordial relations between individuals or groups in a violent dispute.

Reconciliation should be able to heal long animosities between conflicting parties, as this helps in developing a shared feeling of a common history that can be accommodated by both sides and reduces feelings of blame, mistrust and antagonism (Staub et al., 2003). A reduce feeling of blame should also imply political tolerance, which should foster the commitment of leaders to coexist in peace with people whose ideas are different from theirs. Reconciliation should be more feasible if people are able to form working political relationships that cross divisions.

Some form of apology or public acknowledgement of wrong doing is necessary for healing the wounds of the past (Hamber, 2007; Kaminer, Stein, Mbanga, \& Dirwayi, 2001). 
Ibeanu (2003), like Kaminer et al. (2001), suggest that it is reciprocal recognition that is the bases of relieve and freedom in reconciliation, without which the victims continue to feel that they still exist in a relationship of bondage with their oppressors. In some cultures in Africa, like in Sierra Leone, Rwanda and South Africa, reconciliation is not limited to simplistic verbal utterances or binding agreements (Hamber, 2002, 2007).

The notion of reconciliation within African societies varies from one culture to the other and is often characterised by different cleansing rituals to reinstate the victims and the oppressors within different communities in line with their cultures (Quinn, 2006). Reconciliation is symbolised through various rituals like blood pact alliances, marriages, intimate friendships, eating and drinking and the exchange of gifts, negotiated by the custodians of these traditions (Hancock \& Zeren, 2010; Quinn, 2006).

According to scholarly works, reconciliation can hardly be achieved within a win-lose frame work which is represented in liberal and neo-liberal ideas of retributive justice and often too Universalist, which tend to be limited to the individual wellbeing against communal harmony (Young, 2002). Gray (1995), a liberal philosopher, in his analysis of liberalism, describes the liberal ideas as being individualist, egalitarian and Universalist. He further asserts that, while the egalitarian component assigns the same moral worth and status to all individuals, the Universalist nature of liberalism underpins the moral unity of all humans, an idea which marginalises other cultural differences. Generally, liberalism has come to be represented by views such as believing in equality and individual human rights (Young, 2002).

Other scholars, like Adams (1998), challenge liberal views, which to him limit the wellbeing of society strictly on individual human rights perception. According to him, society is an embodiment of all, in which individuals are obliged to promote the common good of everybody (Adams, 1998). In line with Adams, Koerner (1985) also asserts that liberalism is nothing but a pursuit of progress and material gains by those who promote it, which undermines the traditional values rooted within communities to ensure continuity (Koerner 1985).

Drawing from the above, it is our opinion that liberalism and neo-liberalism have an overlap which directly determines the formation of peacebuilding institutions in Africa, like the TRCs. While the term neo-liberalism has come to represent different usages to different scholars depending from the angle from which the concept is approached, neo-liberalism is far more an economic idea which attempts to disentangle the state from the private enterprise in favour of free market economy.

To argue that TRC also take roots from neo-liberal ideologies, we do not imply that these institutions are largely developed within the framework of neo-liberalism, but rather they appropriate certain characteristics of liberal and neo-liberal philosophies. Even in the application of neo-liberalism within the free market economy, the emphasis on 
the individual and universalism becomes apparent, as it considers the individual alone has the autonomy to ascertain a better choice in providing for his needs.

In addition, laws under neo-liberalism are seen as universal norms through which people could negotiate with each other (Gershon, 2011). This becomes culturally insensitive since culture within this framework is more of a trait that engenders alliances, which neglects the context specifics among different societies. Culture from a neo-liberal perspective, as Gershon puts it, serves not to explain context in which it operates, but rather to explain individual behaviours. It is within this framework that we argue that the structures of peacebuilding in Africa, like TRCs, appropriate certain characteristics of liberal and neo-liberal ideologies that do not resonate with the local culture of the people. To understand the TRC in South Africa and the gacaca courts in Rwanda, we try to high light how the inclusion of indigenous cultural elements in their formation promoted the healing of animosity, reduced feeling of blame, a sense of common history and ability of the perpetrators and victims to coexist. We use the aforementioned gacaca traditional system of Rwanda and the case of South Africa and the concept of Ubuntu to highlight how cultural consideration accounted specifically for the success of South African experiment of TRC, a component which has been lacking in similar experiences in other African countries like in Ivory Coast. After examining the analytical framework, it will be imperative at this juncture to focus our discussion on Rwanda and South Africa.

\section{The Rwandan Case}

Within the indigenous customs and values in Africa, there are diverse forms and approaches in keeping the societal bond, which include retributive, restorative or reparative justice as against the over reliance on the retributive model of the tribunals or some TRCs which do not resonate with the people in context (Quinn, 2006). The experiment of traditional courts in Rwanda in dispensing justice to the post 1994 genocide trials could be seen as an attempt to include cultural considerations in consolidating peace in post conflicts zones that resonates with the culture of the people.

Much ink has flown on the Rwandan fratricidal carnage but it is relevant to summarise its headlines here. The Rwandan genocide was the mass killing of Tutsi and moderate Hutu in Rwanda by members of the Hutu majority. During the approximately 100-day period from the 7 April to 15 July 1994, it is estimated that an estimated 500.000$1,000.000$ Rwandans were killed in the conflagration, constituting as much as $20 \%$ of the country's total population and $70 \%$ of the Tutsi then living in Rwanda. It is suggested that the genocide was planned by members of the core political elite known as the akazu, many of whom occupied positions at top levels of the national government.

Perpetrators came from the ranks of the Rwandan Army, the National Police (gendarmerie) and government backed militias including the Interahamwe and Impuzamugambi 
and the Hutu civilian populations. The genocide took place in the context of the Rwandan Civil War, an ongoing conflict that began in 1990 between the Hutu led government and the Rwandan Patriotic Front (RPF), which was largely composed of Tutsi refugees whose families had fled to Uganda following the earlier waves of Hutu violence against the Tutsi. International pressure on the Hutu-led government Juvenal Habyarimana resulted in a cease fire in 1993 with a roadmap to implement the Arusha Accords that would create a power sharing government with RPF. This agreement displeased many conservative Hutu, including members of the akazu, who viewed it as conceding to enemy demands. Among the broader Hutu populace, the RPF military campaigns had also intensified support for the so called "Hutu power" ideology, which portrayed the RPF as an alien force intent on reinstating the Tutsi monarchy and enslaving the Hutus, a prospect that met with extreme opposition.

A few years after the genocide, the gacaca courts were used as a form of traditional conflict management, to seek restorative justice mediated by chiefs and tribal elders to handle crimes of the 1994 genocide. They dispensed justice according to traditional norms which include cleansing ceremonies which the subjects hold sacred (Quinn, 2006). To resolve the issue of long awaited trials in Rwanda, and also in a bid to achieve sincere reconciliation at the grass roots level, the Rwandan Government re-established the traditional community court systems called gacaca. Within this traditional court system, communities at the grass roots are empowered to elect local judges to try Rwandans who were accused of crimes during the genocide. The courts generally give low sentences in situations where the accused was sorry for his guilt and asked for forgiveness from the community and, in most cases, victims who apologised went home without further penalties (Quinn, 2006). Over 1.2million cases went through an estimated 12000 gacaca courts that were established nationwide.

To realise the objective of reconciliation, different approaches were taken by the Rwandan government among which included Ingando, a programme for peace education that trained about 90.000 Rwandans, clarifying Rwandan history and the origin of conflicts that led to the genocide. There was also Itorero, established in 2007, which was aimed at promoting Rwandan values and build leaders who strive for community development. The government, to further consolidate peace, organised seminars which were aimed at educating community based leaders, political parties, youths and women in trauma counselling, conflict management and early signals of conflict. National summits and research works have been sponsored to investigate and sensitize the causes and prevention of conflict in Rwanda (Quinn, 2006).

Traditional approaches were case specific. Every region had their own values which guide the common interest of communal solidarity, which took precedence over individual human rights as emphasised by retributive justice mechanisms (Quinn, 2006). These indigenous approaches built relationships and a common sense of belonging. 
As Hancock and Zeren (2010) noted, retributive justice has always been least popular among African systems and often came only when all other avenues of socializing the guilty had proven abortive. Even in cases where retributive methods were emphasised and pardon was feasible only if damages were paid, the general idea had always been to strike a balance of reconciliation (Quinn, 2006). Native African authorities are ostensibly believed to represent the whole communities beyond political differences, embodying the will of everybody without leaving out anyone. This was in contrast with views that their incorporation and legitimization could reinforce ethnic cleavages to the detriment of integration (Binsbergen, 1987; Mbiti, 2002). They exert an enormous control over their subject even beyond their geographical confinements. As Mbiti (2002) argues, for those Africans who live out of their local communities, modernity can only affect to a limited extent their material orientation and language, but their general perception is still informed by traditional and cultural values.

\section{The South African TRC}

Between 1948 and 1994, Dr. Malan institutionalised and legitimated the obnoxious Apartheid system in South Africa. During this period, the majority of South Africans, who were mostly blacks, went through all kind of torture and marginalisation. In 1998, there was the need to reconcile the different factions of the country that were still carrying the scars of the conflict. In this case study, we examine the institution of TRC in post-Apartheid South Africa, its formation and its underlying cultural concept of Ubuntu that is grounded within indigenous South African cultures. We also examine the religious character of the commission which accounted why its implementation was relatively a success story within the experiments of TRC in Africa.

Shortly after the collapse of the Apartheid regime and the election of Nelson Mandela in 1994, through a broad base consultation with the civil society and local leaders, the South African parliament passed the promotion of a National Unity Act (Hancock \& Zeren, 2010). Under the leadership of Archbishop Desmond Tutu, the TRC was inaugurated in December 1995 to foster national unity and integration of survivors and perpetrators and also to seek accountability. TRC was guided by the new transitional constitution which also placed emphasis on cultural leaders and the customs they represent.

One of the provisions within the constitution stated: "past divisions can now be addressed on the bases that there is need for understanding but not vengeance, a need for reparation but not retaliation, a need for Ubuntu and not victimisation" (Vora \& Vora, 2004, p. 4). Amongst other things, the act also maintained that "in order to advance such reconciliation and reconstruction, Amnesty shall be granted in respect to Acts, omissions and offenses associated with political objectives and committed in the course of conflict of the past" (Vora \& Vora, 2004, p. 4). To achieve this goal, three commissions 
were formed within the TRC: the Human Right violation committee (HRVC), the Amnesty Committee (AC) and the Committee of Reparation and Rehabilitation (Hancock \& Zeren, 2010). Beyond this, the TRC used restorative justice in handling the issue of impunity and encouraged people to forgive rather than demand retribution.

The concept of Ubuntu within the South African society resonates with a communal spirit and asserts that society, not a transcendent being, gives human beings their humanity (Carver, 2008). Ubuntu creates an atmosphere of shared mutual caring for all. Ubuntu emphasises a kind of socialisation where individuals within a given community empathise and also seek to promote the collective prosperity of all. As a political concept, Ubuntu carries elements of socialism that upholds the redistribution of wealth, very much in line to redistributive policies of liberal and neo-liberal undertone. The overall sense of Ubuntu is a belief in a universal bond of sharing that connects all humanity.

By applying Ubuntu, amnesties for crimes committed by either side were granted in return for a full account of the violence on which such pleas were made. According to Vora and Vora (2004), this was fully in line with Ubuntu that was rooted in the culture of the people. In order to ascertain accountability in the construct of the TRC, efforts were made to investigate crimes committed by both parties from 1960-1994. This also eliminated the notion of victor's justice (using different set of rules to determine right from wrong depending on whether the individuals in question belong to the oppressor or the victim's side) that could have potentially ruined the exercise.

Hearings were made in public, areas within the reach of the general public (like churches and town halls), away from the court rooms. This not only give victims a sense of belonging, but also gave them a sense of active participation, which reduced immensely their feeling of animosity towards the perpetrators (Hancock \& Zeren, 2010). As the TRC pursued national unity for all, sincere reconciliation and forgiveness became the ultimate goal, which was achieved through a careful blend of restorative and retributive justice models. As Carver (2008) asserts, forgiveness does not actually means in this case just forgiving the perpetrator, since it does not replace justice. Rather, it implies perpetrators accepting responsibility for the acts and in an apologetic manner.

In other words, forgiveness does not exclude the need for moral accountability, but rather attempt at genuinely healing the wounds of the past for effective societal social repairs, in the spirit of Ubuntu (Carver, 2008). Its non-legal style situates the process to the understanding of the local indigenous people who could see that the proceedings were inherent with their cultures. The open space narrative in the process, which often took place in town halls and churches led by the Archbishop Desmond Tutu, was also inherent in the long documented oral history of the continent. The role of religion was also instrumental in the South African TRC. 


\section{The Religious Factor in the South African TRC}

Religion has always played an ambivalent role in conflict situations. At one end, it is at the very heart of the conflict and at the other end it is used for reconciliation. However, the role of religion in the reconciliation in South Africa cannot be underscored. As far as the religion and the urge for vengeance is concern, Jacoby (1983) argues that religion somehow plays a role as it directs people's minds towards the ideas of love and mercy. Thus, religion in a way impacts on the cultural interpretations of legal traditions as it encourages justice through restorative and distributive forms of justice emphasised by the redemptive character of religion, as they advocate for the forgiveness of transgressors in a bid to enhance societal harmony (Jacoby, 1983). The religious content of the TRC was negotiated by Archbishop Desmond Tutu.

While religion might not have been an initial consideration in the formation of the TRC, the appointment of Desmond Tutu as the chair of the commission gave him the space to negotiate a religious dimension and this relates to how he influenced the hearing sessions towards religious lines. In line with Jacoby's (1983) assertion on the redemptive role of religion, Tutu, from the opening prayers to the homilies, purposely created a scenario that bore resemblance to recognisable church ceremonial practices with a healing tone. The use of religious imagery in South Africa was comforting to many victims (Shore \& Kline, 2006). The role of religion in South Africa has never been limited to the individual salvation and or spiritual life, but the general good of the community. Tutu was able to exploit these values in the search for peace within the TRC frame work, relying on the religious culture of the people (Hancock \& Zeren, 2010).

It is estimated that over a thousand people were interviewed in the process and over 850 people were granted amnesties by the TRC through the various commissions which were given full and independent powers to decide every outcome (Carver, 2008). Religion and Ubuntu were ways to engender sincere societal repairs in an African perspective, not just an attempt to get the people to accept the hard truth that they had to live with their one time enemy of Apartheid. The use of amnesty was partly in line with the cultures of the people grounded in the concept of Ubuntu and not just a way to abandon retributive justice in in favour of it.

\section{Limitations of the Traditional African Systems}

Although we have argued so far that one possible way to improve the functioning of TRCs in Africa is by drawing on their rich cultural values, like the example of Ubuntu in South Africa, these systems are sometimes also flawed with lapses that can hinder any meaningful progress in peacebuilding and also need to be revamped. The relevance of traditional African institutions in peacebuilding is highly contested, especially in the post-colonial era (Osaghae, 1989). These institutions are often seen to be anachronistic, undemocratic, divided and unable to contribute to anything meaningful in the current 
governance crisis within the continent (Beattie, 1967). Also, chieftaincy has been corrupted by colonial powers and the new post-colonial leaders in the continent. Most of these traditional heads have been co-opted into politics along party lines and thus, no longer subject of accountability to their communities (William, 1987).

Western Christianity, with all its trappings, has also contributed to the inherent weaknesses which the traditional African systems have been suffering. Mbiti (2002), while discussing about the search for new values, opines that things fared well with African communalism and religions up to a point in time which things changed. This was when Western religions and values, as well as colonialism, were introduced into the continent. These values have since then affected different African societies in multifarious ways. Traditional African ways of doing things and their understanding of their cosmos were corroded by the new values from without. This has helped greatly to limit the traditional ways of conflict management and reconciliation which up to date remain weak.

\section{Conclusion}

Throughout this work, we have argued that the failure of TRCs in Africa is largely because their implementation often does not take into consideration the cultural values of the indigenous people. As an analytical frame work, we looked at the concepts of reconciliation, liberal and neo-liberal ideas which seemingly have an overlap in the institutionalization of these structures of peace building in Africa. We highlighted how different scholars have seen and understood these concepts. The point of emphasis here is that most TRC emphasizes universalism, individualism and redistributive justice as opposed to indigenous approaches to peacebuilding based on the communal wellbeing for all. This universalized approach undermines cultural differences across different societies.

Using the example of the gacaca traditional courts in Rwanda and the Ubuntu in South Africa, we have argued that African customary laws contain elements of legal traditions in respect to criminal law. However, we see that within the African systems, these elements of legality places emphasis on reconciliation as against retributive justice, whose usage is always as a last resort. We used the South African concept of Ubuntu and the gacaca traditional courts in Rwanda to illustrate this position. In Ubuntu, acts of violence become the responsibility of the entire community; any harm to a part is seen as harm to the whole. The role of justice within this context in South Africa was not perceived as a punitive major, but rather an act of restoration for societal good (Quinn, 2006). We also looked at the religious character of the South African TRC which was very instrumental in healing the wounds of Apartheid. This was largely due the charismatic nature of Desmond Tutu.

On a final note, this paper does not try to present African systems as an ideal solution to African problems. They too are characterized by a series of short comings. These institutions are often very divisive, out of touch with new ideas and undemocratic to 
produce any meaningful effect on peacebuilding. It is either these African systems are too decentralized, which slows down decision making process or too centralized, which concentrates power to just one individual. In such circumstances, the concept of communal good becomes a subject of doubt. In any case, no single approach will appear to be an absolute solution to the crisis in Africa.

\section{References}

1. Adams, I. (1998). Ideology and politics in Britain today. Manchester: Manchester University Press.

2. Adedeji, A. (1999). Comprehending and mastering African conflicts: The search for sustainable peace and good governance. London: Zed Books.

3. Beattie, J. H. (1967). Checks on the Abuse of Political Power in Some African States: a Preliminary Framework for Analysis. In R. Cohen and J. Middleton (Eds), Comparative political systems: Studies of politics and pre-industrial societies (pp. 355-374). Austin: University of Texas Press.

4. Binsbergen, W.(1987). Chiefs and the state in independentZambia: Exploring the Zambian national press. The Journal of Legal Pluralism and Unofficial Law, 19(25-26), 139-201.

5. Boaduo, N. A. P. (2010). Epistemological analysis: conflict and resolution in Africa. Journal of Pan African Studies, 3(10), 168-180.

6. Carver, D. H. (2008). The Xhosa and the Truth and Reconciliation Commission: African Ways. Tribal LJ, 8, 34-52.

7. Gershon, I. (2011). Neoliberal agency. Current Anthropology, 52(4), 537-555.

8. Gray, J. (1995). Liberalism. Minneapolis: University of Minnesota Press.

9. Hamber, B. (2002). Ere their story die': truth, justice and reconciliation in South Africa. Race and Class, 44(1), pp. 61-80

10. Hamber, B. (2007). Forgiveness and reconciliation: Paradise lost or pragmatism?. Peace and Conflict, 13(1), 115-125.

11. Hancock, K., \& Zeren, A. (2010). Whose truth, whose justice, Religious and cultural traditions in transitional justice. Journal of Religion conflict and peace, 4(1), 1-16.

12. Hayner, P. (1999). In pursuit of justice and reconciliation: Contributions of truth telling. Comparative peace processes in Latin America, 2(4), 363-383.

13. Hayner, P. (2002). Unspeakable truths: Facing the challenges of truth commissions. New York: Routledge.

14. Humphrey, M. (2003). International intervention, justice and national reconciliation: the role of the ICTY and ICTR in Bosnia and Rwanda. Journal of Human Rights, 2(4), 495-505.

15. Ibeanu, O. (2003). Aguleri-Umuleri Conflict in Anambra State. Civil Society and Ethnic Conflict Management in Nigeria. Ibadan: Spectrum.

16. Jacoby, S. (1983). Wild Justice: the evolution of revenge. New York: Harpers and Row.

17. Juma, L. (2002). Reconciling African Customary Law and Human Rights in Kenya: Making a Case for Institutional Reformation and Revitalization of Customary Adjudication Processes. Thomas L. Rev., 14, 459-460. 
18. Kaminer, D., Stein, D. J., Mbanga, I., \& Zungu-Dirwayi, N. (2001). The Truth and Reconciliation Commission in South Africa: relation to psychiatric status and forgiveness among survivors of human rights abuses. The British Journal of Psychiatry, 178(4), 373-377.

19. Kirmayer, l. (2004). The cultural diversity of healing. Meaning, metaphor and mechanism. British medical Bulletin, 69(1), 33- 48.

20. Koerner, K. (1985). Liberalism and its critics. Oxford: Taylor and Francis.

21. Kriesberg, L. (2007). Constructive conflicts: From escalation to resolution. Oxford: Rowman \& Littlefield.

22. Kyed, H. M. (2006). New Sites of Citizenship: Recognition of Traditional Authority and Group-based Citizenship in Mozambique. Journal of Southern African Studies, 32(3), 563-581.

23. Mbiti, S. (2002). African religion and Philosophy. Nairobi: East African Educational Publishers.

24. Murphy, C. (2010). A moral theory of political reconciliation. Cambridge: Cambridge University Press.

25. Osaghae, E. E. (1989). The passage from the Past to the Present in African Political Thought: The Question of Relevance in African Political Thought and Institutions. Lagos: Centre for Black and African Arts and Civilization.

26. Philpott, D. (2006). The politics of past evil religion, reconciliation and the dilemmas of transitional justice. Notre Dame: University of Notre Dame Press.

27. Quinn, J. R. (2006). Beyond Truth Commissions: Indigenous Reconciliation in Uganda. The Review of Faith \& International Affairs, 4(1), 31-37.

28. Shore, M., \& Kline, S. (2006). The ambiguous role of religion in the South African Truth and Reconciliation Commission. Peace \& Change, 31(3), 309-332.

29. Staub, E., Pearlman, L. A., \& Miller, V. (2003). Healing the roots of genocide in Rwanda. Peace Review, 15(3), 287-294.

30. Vora, J. A., \& Vora, E. (2004). The Effectiveness of South Africa's Truth and Reconciliation Commission Perceptions of Xhosa, Afrikaner and English South Africans. Journal of Black Studies, 34(3), 301-322.

31. William, M. (1987). Partitioned royalty: the evolution of Hausa chiefs in Nigeria and Niger. The Journal of Modern African Studies, 25(2), 233-258.

32. Young, S. (2002). Beyond Rawls: An Analysis of the concept of political liberalism. Lanham: University Press of America.

33. Zartman, I. W. (2000). Ripeness: The Hurting Stalemate and Beyond. In P. Stern and D. Druckman (Eds.), International Conflict Resolution after the Cold War (pp. 225-250). Washington: National Academy Pres. 